\title{
Grading obesity hypoventilation syndrome severity
}

\section{To the Editors:}

Obesity hypoventilation syndrome (OHS) is commonly defined as a combination of obesity (body mass index (BMI) $>30 \mathrm{~kg} \cdot \mathrm{m}^{-2}$ ), waking arterial hypercapnia (arterial carbon dioxide tension $\left.\left(\mathrm{Pa}_{\mathrm{a}} \mathrm{CO}_{2}\right)>6.0 \mathrm{kPa}(45 \mathrm{mmHg})\right)$ and sleepdisordered breathing. Essential to the diagnosis is exclusion of other causes of alveolar hypoventilation [1]. The lack of a standardised definition of OHS in general, and of OHSobstructive sleep apnoea relationships in particular, leads to confusion.

One of the main aspects that has not been clarified is the assessment of OHS severity. This appears to be directly related to the degree of hypercapnia, the degree of hypoxaemia and the presence of complications [2, 3]. Nevertheless, defined criteria to quantify OHS severity do not exist in the literature. The question is: are all OHS cases supposedly severe? We think there are several approaches for determining the level of OHS severity.

One approach would be to grade OHS severity according to the degree of impairment of functional respiratory parameters, such as hypercapnia or hypoxaemia. For example, a patient with a $\mathrm{Pa}_{1} \mathrm{CO}_{2}$ of $6.1-8.0 \mathrm{kPa}(46-60 \mathrm{mmHg})$ could be considered as mild, $8.1-10.6 \mathrm{kPa}(61-80 \mathrm{mmHg})$ as moderate, and $>10.6 \mathrm{kPa}(80 \mathrm{mmHg})$ as severe.

One could also grade OHS severity according to the BMI or spirometric findings. For example, a patient with a BMI of 30$40 \mathrm{~kg} \cdot \mathrm{m}^{-2}$ could be considered as mild, $40-50 \mathrm{~kg} \cdot \mathrm{m}^{-2}$ as moderate and $>50 \mathrm{~kg} \cdot \mathrm{m}^{-2}$ as severe. Based on spirometric findings, the OHS could be classified as severe if a pulmonary function test reveals a severe restrictive impairment.

Another approach to scoring OHS severity could be based on polysomnographic findings, such as the percentage of time spent with arterial oxygen saturation $<90 \%$, the respiratory disturbance index or the apnoea/hypopnoea index. The presence of complications could also be taken into account. In this case, we could grade as severe OHS patients with pulmonary hypertension, cor pulmonale, left ventricular failure, polycythaemia or a history of intensive care unit hospitalisations.

A quite different approach could be based on an "asthmacontrol" strategy for OHS patients. We could look at OHS not only in terms of severity but also in terms of response to treatment. We could consider OHS patients as controlled, partly controlled or uncontrolled. Attaining optimal OHS control would be an important goal of all physicians attending to those with OHS. But what is a well-controlled OHS patient? In our opinion, OHS could be considered well controlled when there is: 1) absence of symptoms; 2) no nocturnal or early morning awaking; 3) good tolerance to noninvasive ventilation; 4) absence of respiratory insufficiency; and 5) appreciation by the patient and their physician that the OHS is well controlled.

\begin{tabular}{|c|c|c|c|}
\hline \multirow[t]{2}{*}{ TABLE 1} & \multicolumn{3}{|c|}{$\begin{array}{l}\text { Factors influencing severity of obesity } \\
\text { hypoventilation syndrome: a proposal for } \\
\text { classification based on functional parameters }\end{array}$} \\
\hline & Mild & Moderate & Severe \\
\hline $\mathrm{Pa}, \mathrm{CO}_{2} \mathrm{mmHg}$ & $46-60$ & $60-80$ & $\geqslant 80$ \\
\hline $\mathrm{Pa}, \mathrm{O}_{2} \mathrm{mmHg}$ & $\geqslant 70$ & $60-70$ & $\leqslant 60$ \\
\hline BMI $\mathbf{k g} \cdot \mathrm{m}^{-2}$ & $30-40$ & $40-50$ & $\geqslant 50$ \\
\hline AHI events $\cdot h^{-1}$ & $<5$ & $5-15$ & $>15$ \\
\hline $\begin{array}{l}\text { Complications or } \\
\text { comorbidities }\end{array}$ & No & No & Yes \\
\hline
\end{tabular}

\begin{tabular}{|c|c|c|c|}
\hline \multirow[t]{2}{*}{ TABLE 2} & \multicolumn{3}{|c|}{$\begin{array}{l}\text { Factors influencing severity of obesity } \\
\text { hypoventilation syndrome: a proposal for } \\
\text { classification based on disease control }\end{array}$} \\
\hline & Controlled & $\begin{array}{c}\text { Partly } \\
\text { controlled }\end{array}$ & Uncontrolled \\
\hline $\mathrm{Pa}, \mathrm{CO}_{2} \mathrm{mmHg}$ & Normal & $46-60$ & $>60$ \\
\hline $\mathrm{Pa}, \mathrm{O}_{2} \mathrm{mmHg}$ & Normal & Normal & $<60$ \\
\hline Tolerance of NIV & Yes & Partial & No \\
\hline Symptoms & No & $\begin{array}{r}\text { No, or only } \\
\text { nocturnal }\end{array}$ & Yes \\
\hline
\end{tabular}

$\mathrm{Pa}_{\mathrm{a}} \mathrm{CO}_{2}$ : arterial carbon dioxide tension; $\mathrm{Pa}_{\mathrm{a}} \mathrm{O}_{2}$ : arterial oxygen tension; NIV noninvasive ventilation. $1 \mathrm{mmHg}=0.133 \mathrm{kPa}$.

It seems reasonable to suggest that management of obesity hypoventilation syndrome patients could be different according to the severity of the disease and that not all obesity hypoventilation syndrome patients have the same level of severity. Perhaps a multifactorial approach, involving several aspects concerning the severity of obesity hypoventilation syndrome, would be necessary. Tables 1 and 2 show proposals for classification based on functional parameters or disease control. The strategy of increasing treatment until control is achieved could be a new approach to obesity hypoventilation syndrome management.

\section{Cabrera Lacalzada and S. Díaz-Lobato}

Pneumological Service, Ramón y Cajal Teaching Hospital, Madrid, Spain.

\section{STATEMENT OF INTEREST}

None declared. 


\section{REFERENCES}

1 Mokhlesi B, Kryger MH, Grunstein RR. Assessment and management of patients with obesity hypoventilation syndrome. Proc Am Thorac Soc 2008; 5: 218-225.

2 Subramanian S, Strohl KP. A management guideline for obesity-hypoventilation syndromes. Sleep Breath 1999; 3: 131-138.
3 Campo A, Frühbeck G, Zulueta JJ, et al. Hyperleptinaemia, respiratory drive and hypercapnic response in obese patients. Eur Respir J 2007; 30: 223-231.

\section{Flow-independent nitric oxide parameters in infants with and without recurrent wheeze}

\section{To the Editors:}

Flow-independent nitric oxide parameters (FIPs) have given an insight into airway physiology and pathology in adults and children [1]. Measurements of fractional exhaled nitric oxide ( FeNO) are sensitive to respiratory symptoms and environmental exposures in infants [2, 3]; therefore, it would be reasonable to hypothesise that FIPs could extend current understanding about airway pathology in early life. Measurements of FeNO at different expiratory flows are needed to estimate FIPs and, given the challenge in measuring FeNO in infants, it is not surprising that the FIP literature in infants is limited to a single study of five healthy individuals [4]. We measured FeNO at 11 and $40 \mathrm{~mL} \cdot \mathrm{s}^{-1}$ in 14 infants with and without recurrent wheeze as part of a larger methodological study [5]. We have reanalysed our data, derived FIPs, and present our results herein.

The present study population included 14 infants, ten of which were males, of whom seven infants had $\geqslant 3$ episodes of wheeze ever and seven were nonwheezing controls. The modified single-breath technique was used, as has been described in detail by our group elsewhere $[5,6]$. Exhaled nitric oxide was measured online using a chemiluminescence analyser (NOA 280; Seivers Instruments Inc., Boulder, CO, USA). The two-point linear method of Silkoff was used to determine the concentration of nitric oxide in the airway wall (Caw,NO; in ppb) and the diffusion capacity of nitric oxide from the airway wall $\left(D a w, N O\right.$; in $\left.\mathrm{nL} \cdot \mathrm{s}^{-1} \cdot \mathrm{ppb}^{-1}\right)$. This method has previously been validated in young infants, in whom an inverse and linear relationship was demonstrated between FENO and three expiratory flows between 15 and $50 \mathrm{~mL} \cdot \mathrm{s}^{-1}$ [4].

The median (range) age of participants was 33 (19-80) weeks, the median (range) height $71(65,80) \mathrm{cm}$ and the median (range) weight $9.3(6.4,15.4) \mathrm{kg}$. Table 1 presents the FENO values at 11 and $40 \mathrm{~mL} \cdot \mathrm{s}^{-1}$. We have previously reported flow dependence of FENO in infants [5]. There were no relationships between FIPs and sex, age, height or weight. The median (range) Caw,NO for wheezers and controls were 79 (19-245) ppb and 37 (14-68) ppb, respectively. The median (range) of Daw,NO for wheezers and controls were 33

\begin{tabular}{|c|c|c|}
\hline \multirow{2}{*}{$\begin{array}{l}\text { Wheeze status in } \\
\text { infancy }\end{array}$} & \multicolumn{2}{|c|}{ Exhaled NO ppb } \\
\hline & At $11 \mathrm{~mL} \cdot \mathrm{s}^{-1}$ & At $40 \mathrm{~mL} \cdot \mathrm{s}^{-1}$ \\
\hline Nonwheezer & 28.00 & 24.43 \\
\hline Nonwheezer & 51.23 & 31.53 \\
\hline Nonwheezer & 28.85 & 23.10 \\
\hline Nonwheezer & 58.00 & 42.05 \\
\hline Nonwheezer & 32.63 & 25.05 \\
\hline Nonwheezer & 50.25 & 42.50 \\
\hline Nonwheezer & 11.85 & 8.60 \\
\hline Wheezer & 19.90 & 15.37 \\
\hline Wheezer & 106.97 & 43.00 \\
\hline Wheezer & 59.00 & 35.47 \\
\hline Wheezer & 47.40 & 37.80 \\
\hline Wheezer & 78.50 & 47.45 \\
\hline Wheezer & 57.85 & 26.90 \\
\hline Wheezer ${ }^{\#}$ & 17.80 & 15.75 \\
\hline
\end{tabular}

$(8-212) \mathrm{nL} \cdot \mathrm{s}^{-1} \cdot \mathrm{ppb}^{-1}$ and $85(35-188) \mathrm{nL} \cdot \mathrm{s}^{-1} \cdot \mathrm{ppb}^{-1}$, respectively. Differences in FIPs between the two groups were not significant. Maternal atopy was determined using the skinprick test. Six mothers of controls were atopic and one mother of a wheezing infant was atopic (Chi squared value 6.2; $p=0.013)$. A total of 12 individuals were followed to age 4 yrs; wheeze persisted in five out of the six wheezers, and was not reported in any of the six controls.

This is the first study to report FIPs in infants with a history of wheeze, most of whom had persistent wheeze by age 4 yrs. Given the small numbers of infants studied and the wide range of FIP values measured, our study was underpowered and the lack of a significant difference in FIPs between the groups was expected. 